\section{Diagnosis of closed neural tube defects by ultrasound in second trimester of pregnancy}

By applying the techniques of maternal serum alpha-fetoprotein (AFP) screening and amniotic fluid AFP studies it is now possible to detect over $90 \%$ of open fetal neural tube defects ${ }^{12}$ early in the second trimester of pregnancy. Campbell ${ }^{3}$ has reported similar success rates in visualising both anencephaly and open spinal defects by ultrasound at this stage of pregnancy in "at risk" patients. In general, AFP studies do not identify fetuses with closed defects, nor have there been any reports of the ultrasound diagnosis of such cases before 20 weeks. We describe two cases of closed defects diagnosed by ultrasound at 18 weeks.

\section{Case reports}

Case 1-A 27-year-old para $2+2$ was referred because her first baby, who had died shortly after birth, had had a large open spinal defect. Her second child had been normal. In her current pregnancy an ultrasonic examination at 18 weeks showed appreciable widening of the normal cervical spinal echoes, and a well-defined 2-cm diameter cystic area "attached" to the lowe occipital area and the upper cervical spine (figure). The biparietal diameter of the fetal head was within normal limits, and the ventricular echoes appeared normal, as did the remainder of the spine. The amniotic fluid AFP concentration was $8 \mathrm{mg} / \mathrm{l}$, well within the normal range for 18 weeks.

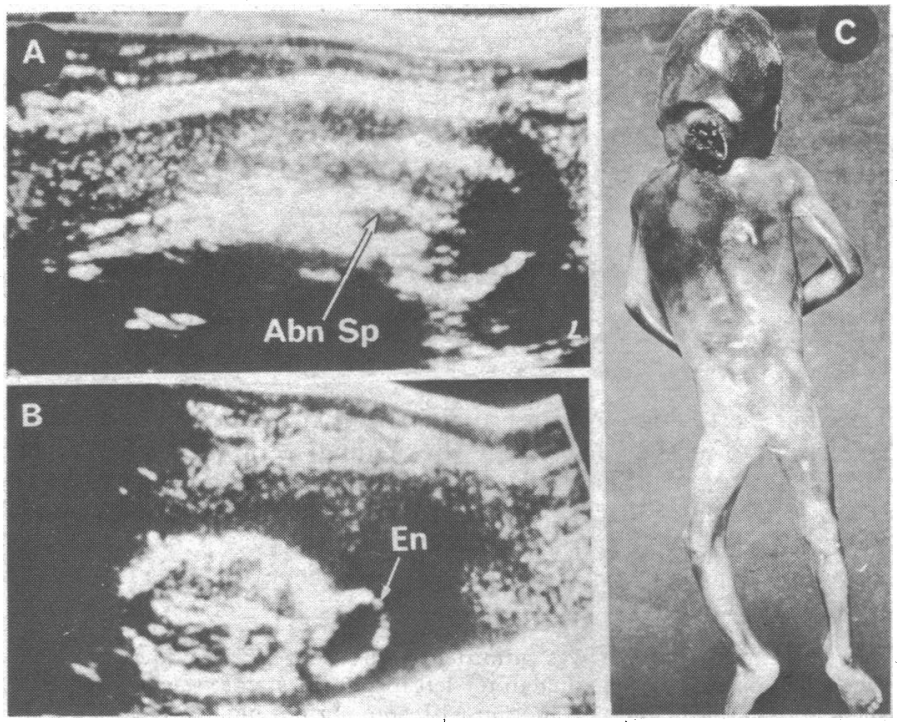

Section A shows a longitudinal scan of the fetus (case 1) along the spina canal. At its upper end the canal is abnormally wide (Abn Sp). In B a cystic structure, the encephalocele (En), is seen attached to the lower occiput, and $C$ shows the fetus after therapeutic abortion. The encephalocele, which ruptured during delivery, was completely covered by skin, as was the spinal canal.

In view of the conflicting evidence of a neural tube defect, the ultrasonic scan was repeated and the previous findings were confirmed. After detailed counselling, the pregnancy was terminated. Examination of the aborted fetus showed a completely skin-covered occipital encephalocele. The cervical spine was abnormally wide and the laminae were of cartilagenous rather than bony tissue. The lower spine was normal.

Case 2-A 31-year-old para $1+0$ was referred at 18 weeks because her previous pregnancy had resulted in a mentally normal but severely physically handicapped child, whose abnormalities had included extensive spina bifida occulta, gross scoliosis, and unilateral absence of ribs. On the basis of severa ultrasonic examinations a small low spinal defect and a large exomphalos were provisionally diagnosed. Two amniotic fluid AFP estimates were between the third and fourth SD levels respectively-that is, not in the range normally associated with an open neural tube defect. Because of the ultrasound findings and the existing burden of a handicapped child, the pregnancy was terminated. The presence of an exomphalos was confirmed and its intact sac found to contain the liver. No obvious lesion of the fetal back was seen but dissection showed spina bifida occulta of the lower lumbar and sacral regions.

\section{Comment}

Over $10 \%$ of neural tube defects are covered by skin, the lesions ranging from small innocuous areas of spina bifida occulta to large myeloceles and encephaloceles, many of which result in major handicap. ${ }^{24}$ Since the skin cover precludes the permeation of AFP from the fetal cerebrospinal fluid into the amniotic cavity, AFP studies have been unhelpful in such cases. ${ }^{12}$ Thus diagnostic ultrasound currently offers the only practical alternative for their early detection.

The closed defects described here represent both ends of the range. In the first the neural tube abnormality was major, and early diagnosis and selective termination were therefore clearly justified. The second case, however, poses problems for the future application of ultrasound in this type of diagnosis. Although in this case there was an associated exomphalos, we can foresee the problem when a termination of pregnancy might be considered after the ultrasonic demonstration of a clinically insignificant defect. Despite this cautionary note, we think that diagnostic ultrasound has an important part to play in detecting major closed defects, and we would therefore recommend that a careful examination is made in all "at risk" patients before amniocentesis. Where any doubt exists about the nature and severity of the lesion after these procedures, recourse to fetoscopy would be a useful, though invasive, technique.

We thank Professor C R Whitfield, Dr W R Chatfield, Professor M A Ferguson-Smith, and Dr A A M Gibson for their co-operation and advice. VDH is currently supported by the National Fund for Research into Crippling Diseases.

1 UK Collaborative Study on Alpha-fetoprotein in Relation to Neural Tube Defects, Lancet, 1977, 1, 1323.

2 Ferguson-Smith, M A, et al, Lancet, 1978, in press.

3 Campbell, S, Clinical Obstetrics and Gynecology, 1977, 20, 351.

4 Laurence, K M, Lancet, 1974, 2, 939.

(Accepted 20 fuly 1978)

Department of Midwifery, University of Glasgow, Queen Mother's Hospital, Glasgow G3 8SH

VALERIE D HOOD, MRCOG, research assistant

HUGH P ROBINSON, MRCOG, lecturer

\section{Anuria in pregnancy}

Anuria in late pregnancy is normally associated with hypotension, infection, or severe toxaemia. ${ }^{1}$ Cases without any obvious cause other than the gravid uterus are rare. ${ }^{2-4}$ It seems to be most prevalent in the seventh month of a first pregnancy. ${ }^{3}$ Treatment has been by ureteric catheterisation or nephrostomy. When there has been no antecedent lesion the prognosis for mother and baby has been good except in one case $^{4}$ where the fetus was dead on admission. Pressure by the pregnant uterus on the already dilated ureters has been suggested as a possible cause. ${ }^{2}{ }^{3}$ I report a case of complete anuria lasting 48 hours for no obvious cause. The pregnancy was further complicated by deep vein thrombosis.

\section{Case report}

The patient, a primigravida, was admitted as an emergency after 28 weeks of amenorrhoea. She gave a history of bilateral loin pain, vomiting, and anuria for 36 hours. Before that her antenatal record had been normal. Her past medical history was unremarkable apart from epilepsy controlled with phenobarbitone $30 \mathrm{mg}$ daily. She was afebrile, normotensive, and without oedema. She had bilateral loin tenderness but neither kidney was palpable. The uterus contained a 30-week pregnancy with the baby presenting by the head. The bladder contained only $4 \mathrm{ml}$ of blood-stained urine. Haemoglobin was $14.3 \mathrm{~g} / \mathrm{dl}$, white blood cell count $14.3 \times 10^{9} / 1$. The results of blood chemistry investigations were: sodium $135 \mathrm{mmol}(\mathrm{mEq}) / 1$, potassium 4.5 $\mathrm{mmol}(\mathrm{mEq}) / 1$, chloride $100 \mathrm{mmol}(\mathrm{mEq}) / 1$, bicarbonate $24 \mathrm{mmol}(\mathrm{mEq}) / 1$, urea $13 \mathrm{mmol} / 1(71.7 \mathrm{mg} / 100 \mathrm{ml})$, creatinine $582 \mu \mathrm{mol} / 1(6.6 \mathrm{mg} / 100 \mathrm{ml})$, raised total plasma oestriol at $1699 \mathrm{nmol} / 1(48.9 \mu \mathrm{g} / 100 \mathrm{ml})$, and normal free or unconjugated plasma oestriol at $29 \mathrm{nmol} / 1(840 \mathrm{ng} / 100 \mathrm{ml})$. An intravenous pyelogram showed normal-sized kidneys with delayed nephrograms and no filling of calices after 10 minutes. A renal ultrasound scan showed dilated collecting systems in both kidneys, suggesting bilateral obstruction.

Frusemide $40 \mathrm{mg}$ intravenously had no effect. A central venous pressure 